\title{
Evaluation of functional outcome after osteosynthesis of intra articular distal humerus fracture with pre contoured locking compression plates
}

\author{
Faisal S. Mohammed, Akshay B. Ingale*
}

Department of Orthopaedics, Government Medical College and Hospital, Nagpur, Maharashtra, India

Received: 11 July 2020

Revised: 11 August 2020

Accepted: 20 August 2020

\author{
*Correspondence: \\ Dr. Akshay B. Ingale, \\ E-mail: koolakshay22@gmail.com
}

Copyright: () the author(s), publisher and licensee Medip Academy. This is an open-access article distributed under the terms of the Creative Commons Attribution Non-Commercial License, which permits unrestricted non-commercial use, distribution, and reproduction in any medium, provided the original work is properly cited.

\begin{abstract}
Background: Intra articular distal humerus fractures are challenging and cumbersome to treat. Therefore osteosynthesis of such fractures is required. The aim of our study was to evaluate the functional outcome of intra articular distal humerus fractures $\mathrm{AO}$ type $13 \mathrm{C}$ by osteosynthesis using olecranon osteotomy with pre contoured locking compression plates in orthogonal plate configuration.

Methods: Thirty patients were included in our study comprising of 18 males and 12 females. Mean age was 39.63 years with mean follow up of 34 weeks. 7 were AO type 13C1, 9 were AO type $13 \mathrm{C} 2$ and 14 were AO type $13 \mathrm{C} 3$. Osteosynthesis was done for all fractures by olecranon osteotomy approach. Functional outcome was assessed using mayo elbow performance score.

Results: Mean flexion attained at the end of follow up was 127.56 degrees with mean extensor lag of 7.16 degrees. Mean arc of motion was 120.4 degrees. Mean mayo elbow performance score at the end of follow up was 80.36. Mayo elbow performance score in patients aged less than 40 years of age was not statistically significant as compared to patients more than 40 years of age. Functional outcome was also dependent on fracture subtype.

Conclusions: Osteosynthesis of distal humerus fractures AO type 13C using pre contoured locking compression plates in orthogonal plate configuration by olecranon osteotomy provides excellent visualization of fracture and better functional outcome.
\end{abstract}

Keywords: Intra articular, Distal humerus, Fractures, Olecranon, Osteotomy

\section{INTRODUCTION}

Distal humerus fractures comprise approximately $2 \%$ of all fractures. ${ }^{1,2}$ Fractures of this type usually follows a bimodal age distribution. Peak incidence between 12 and 19 years of age, usually men and in females after 65 years of age. In younger age group fractures occur as a result of high energy mechanism like road traffic accidents, fall from height, sports injuries. On the contrary in elderly age group it occurs as result of low energy mechanism like fall from standing height. ${ }^{2}$ Management of distal humerus fractures has become challenging because of complex and comminuted fracture geometry and osteoporosis.
Principles of osteosynthesis and anatomic restoration were first advocated by Albin Lambotte in 1913. Due to infections, lack of antibiotics and hardware failure this principle failed miserably. Thereafter, conservative management of such fractures was started considering it as 'bag of bones'. ${ }^{3,4,5}$ With years to come controversy regarding management of distal humerus fractures continued. During last 30 years due to better understanding of the anatomy, ground breaking fixation devices and need for postoperative rehabilitation, the outcome of internal fixation have improved significantly. Poor outcomes are mostly due to severe comminution, poor bone stock, prolonged immobilization. The evolution of total elbow 
arthroplasty has become a viable treatment for such type of patients. ${ }^{6}$ As open reduction and internal fixation has been recognized, exposure of fracture fragments and anatomical reduction are of paramount importance. Although many classification systems such as mehne and matta, jupiter are in existence muller $\mathrm{AO}$ classification is frequently used and followed. Various surgical approaches have been described such as olecranon osteotomy, paratricipital, triceps splitting, triceps reflecting anconeus pedicle and bryan morrey each having its own indications and contraindications and advantages and disadvantages. ${ }^{7}$ Excellent articular visualization for reduction and fixation is directed by olecranon osteotomy. ${ }^{8}$ Nonetheless it has disadvantages of nonunion of olecranon and hardware prominence. Due to the advent of locking compression plate these plates are superior to conventional non locking plates especially in osteoporotic patients. ${ }^{9}$ Plate configurations used in distal humerus are parallel, perpendicular or orthogonal and triple plating. As long as principles of internal fixation are concerned none of the plating configuration has been demonstrated as superior clinically. ${ }^{10}$

The aim of our study was to prospectively evaluate functional outcome of intra articular distal humerus fractures $\mathrm{AO}$ type $13 \mathrm{C}$ managed by osteosynthesis, olecranon osteotomy approach and perpendicular plate configuration using locking compression plate.

\section{METHODS}

A prospective study for evaluation of functional outcome of distal humerus fractures managed by osteosynthesis using pre contoured locking compression plates in perpendicular configuration by olecranon osteotomy approach in $\mathrm{AO}$ type $13 \mathrm{C}$ fractures was conducted in the department of orthopaedics, government medical college and hospital, Nagpur. Approval of hospital ethics committee was sought. We looked at distal humerus fractures treated between 2018 and 2020 amounting to 30 patients. There were 18 male and 12 female patients with age ranging from 18 to 65 years. Follow up time ranged from 12 to 52 weeks. Inclusion criteria were closed intra articular distal humerus fractures in age group 18 to 65 years sustained fracture within 2 weeks of surgery without any nerve paralysis and vascular compromise and fracture classification belonging to type AO type 13C. Type 13-C1 fractures covers simple articular, metaphyseal fractures, type 13-C2 are simple articular but have a comminuted metaphysis and lastly type 13-C3 are multi fragmentary articular fractures. The exclusion criteria were compound fractures of grade 2 and grade 3, pathological fractures, patient aged less than 18 years and more than 65 years, patient with severe co morbidities like psychiatric illness, cardiovascular diseases, and cognitive disorders. A thorough history and clinical examination were done of the patient. Other associated injuries were noted. Nerve status was documented for medico-legal purposes. Plain radiographs of the involved limb with adjoining joint were taken. Computed tomography was done to study fracture configuration. Patient was taken to operating table after written informed consent and pre anaesthesia clearance. Patients underwent open reduction and internal fixation with pre contoured posterolateral and medial locking plates in perpendicular configuration by olecranon osteotomy. The patient was placed in lateral decubitus position with arm on a well padded bolster. Under pneumatic tourniquet a standard posterior midline approach was used. A distal apex chevron osteotomy was performed after careful dissection of ulnar nerve(Figure 1).

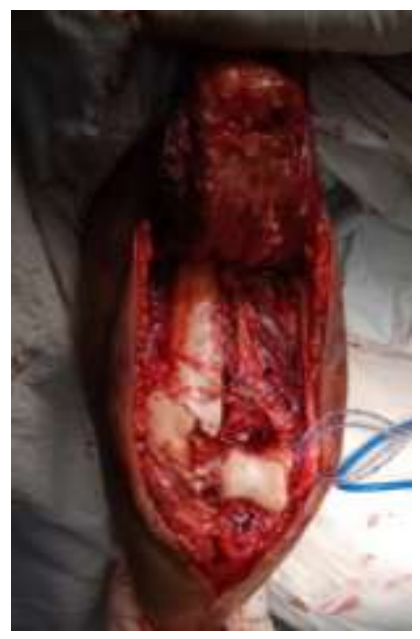

Figure 1: Olecranon osteotomy with ulnar nerve dissected.

After visualization of fracture fragments anatomic articular reduction was achieved and fixed with $4 \mathrm{~mm}$ cannulated cancellous screws. Thereafter, provisional fixation with $\mathrm{k}$ wires was achieved for proximal and distal fragments. Stabilization and fixation was achieved by posterolateral plate for lateral column fixation and medial locking plate for medial column fixation. Olecranon osteotomy was fixed by $\mathrm{k}$ wire and tension band wiring. Meticulous repair of soft tissues was done in layers. Anterior ulnar nerve transposition was done if required. A submuscular drain was used which was removed after 24 hours. Post operatively the limb was placed in above elbow splint and elevation to minimize swelling. Neurovascular status was documented. Injection cefotaxim and amikacin was administered for 5 days and 3 days respectively and discharged on $5^{\text {th }}$ day post operative. Suture removal was done at 14 days. Passive range of motion was started once swelling subsided and continued for 6 weeks and thereafter active-assisted and active range of motion was commenced. Strengthening began at 12 weeks or once there is evidence of radiologic callus formation. . Patients were followed up at 2, 6, 12, 24, 36 weeks with final follow up at 52 weeks. Radiographic assessment was done for any evidence of callus formation, wound complications, ulnar neuropathy, non-union, olecranon osteotomy complications, heterotopic ossification and elbow stiffness. Functional outcome was assessed using mayo elbow performance score(MEPS) consisting of pain intensity, range of motion, stability and function. Mayo elbow performance score greater than 90 is considered 
excellent; score 75 to 89 is good; score 60 to 74 is fair and score less than 60 is poor. Fracture healing was considered as callus formation in two orthogonal planes. No evidence of radiological healing by $16-18$ weeks was considered as delayed union. No union even after 32 weeks was considered as non-union. Statistical analysis was done using descriptive statistics in excel. A p-value of less than 0.05 was considered significant.

\section{RESULTS}

Our study comprised of total 30 patients. Out of which were 18 were male and 12 were female. The mean age was 39.63 years and standard deviation of 13.66 (range 19-62 years). Most common mode of injury was road traffic accident (19 patients) followed by domestic fall (11 patients). Mean follow up period was 34 weeks. Seven were $\mathrm{AO}$ type $13 \mathrm{C} 1,9$ were $\mathrm{AO}$ type $13 \mathrm{C} 2$ and 14 were AO type $13 \mathrm{C} 3$. Mean surgical delay was 5.53 days with standard deviation of 2.62 (range 2-10 days). Mean surgical time was 84.5 minutes with standard deviation of 13.82. Mean flexion attained at the end of follow up was 127.56 degrees with standard deviation of 4.55 degrees. Mean extensor lag of 7.16 degrees with standard deviation of 2.94 degrees was observed. Mean supination was 77.9 degrees with standard deviation of 2.77 and pronation was 72.73 degrees with standard deviation of 2.95. Mean arc of motion was 120.4 degrees with standard deviation of 6.87 . Mean mayo elbow performance score at the end of follow up was 80.36 with standard deviation of 10.65 .
Range of motion attained in patients aged less than 40 years of age was not statistically significant as compared to patients aged more than 40 years of age ( $\mathrm{p}$ value, 0.16 ).

Mayo elbow performance score in patients aged less than 40 years of age was not statistically significant as compared to patients more than 40 years of age ( $\mathrm{p}$ value, $0.07)$.

There was statistically significant difference between arc of motion at elbow of operated and healthy elbows with difference being more in flexion. Pearson co relation coefficient for range of motion with advancing age was 0.35 negative weak co relation. Pearson co relation coefficient for MEPS with advancing age was -0.36 negative weak co relation. Kruskal Wallis test (h-value, 9.2956) were significant for fracture type and arc of motion. Extension lag was also statistically significant in fracture subtype (h-value-6.0024).

With regards to complication two patients had implant prominence with removal of implants done after radiological union was achieved. Two patients had neuropraxia of ulnar nerve fully recovered within 12 weeks. One patient had infection resulting into elbow stiffness. No complication of non union, malunion and heterotopic osssification was seen. Two patients had radiological evidence of elbow arthritis.
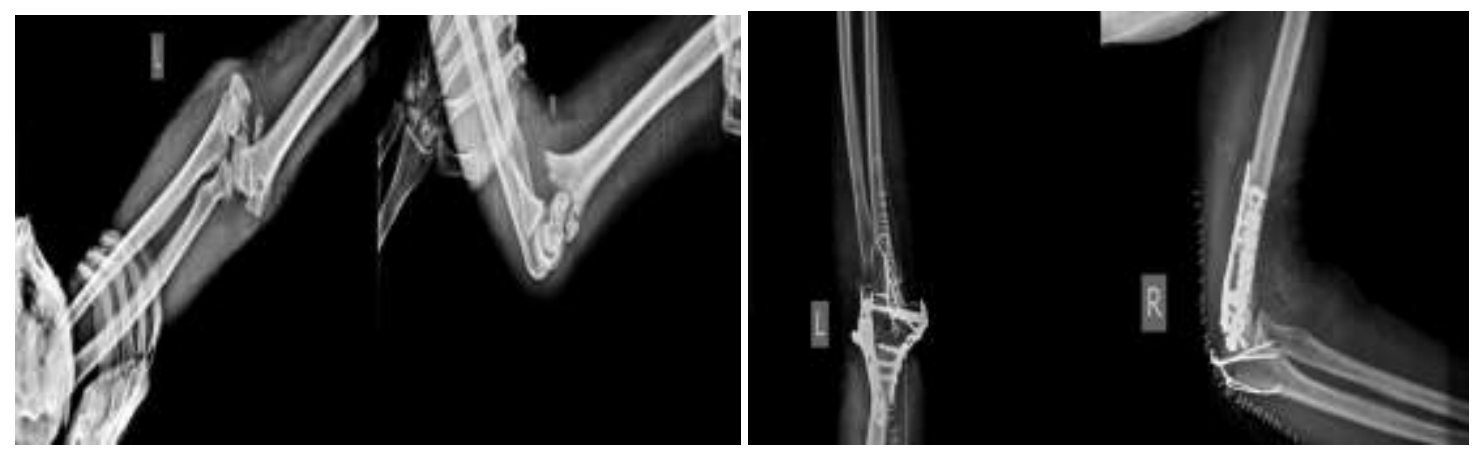

Figure 2: Patient 1, mayo elbow performance score at the end of follow up-83 A) pre-operative X-ray fracture type 13C3, B) post-operative X-Ray.

Table 1: Demographic data and functional outcome for each fracture subtypes.

\begin{tabular}{|c|c|c|c|c|}
\hline & $\begin{array}{l}\text { Fracture } \\
\text { type } 13 \mathrm{C} 1\end{array}$ & $\begin{array}{l}\text { Fracture } \\
\text { type } 13 \mathrm{C} 2\end{array}$ & $\begin{array}{l}\text { Fracture } \\
\text { type } 13 \mathrm{C3}\end{array}$ & Total \\
\hline Mean age (in years) & 37.42 & 41.66 & 39.42 & $39.63+13.66$ \\
\hline Mean surgical delay (in days) & 5.71 & 5.66 & 5.35 & $5.53 \pm 2.62$ \\
\hline Mean surgical time (minutes) & 87 & 74.88 & 89.42 & $84.5 \pm 8.82$ \\
\hline Mean flexion (degrees) & 131.14 & 128.44 & 125.21 & $127.56 \pm 4.53$ \\
\hline Mean extensor lag (degrees) & 5 & 7.11 & 8.28 & $7.16+2.94$ \\
\hline Mean arc of motion(degrees) & 126.14 & 121.33 & 116.92 & $120.4 \pm 6.87$ \\
\hline Mean supination (degrees) & 79.14 & 77.55 & 77.5 & $77.9 \pm 2.77$ \\
\hline Mean pronation (degrees) & 75 & 71.33 & 72.5 & $72.3 \pm 2.95$ \\
\hline Mean MEPS & 89.14 & 83.33 & 74.07 & $80.36 \pm 10.65$ \\
\hline
\end{tabular}


Table 2: Analysis of Mayo Elbow performance score in each fracture subtype.

\begin{tabular}{|lllll|} 
& MEPS & MEPS & MIES & \multicolumn{2}{c|}{$\begin{array}{l}\text { MEPS } \\
\text { Poor }\end{array}$} \\
\hline Type C1 $(\mathbf{n = 7})$ & 3 & 4 & 0 & 0 \\
\hline Type C2 $(\mathbf{n = 9})$ & 3 & 6 & 0 & 0 \\
\hline Type C3 $(\mathbf{n = 1 4})$ & 2 & 5 & 4 & 2 \\
\hline Total=30 & 8 & 15 & 4 & 2 \\
\hline
\end{tabular}
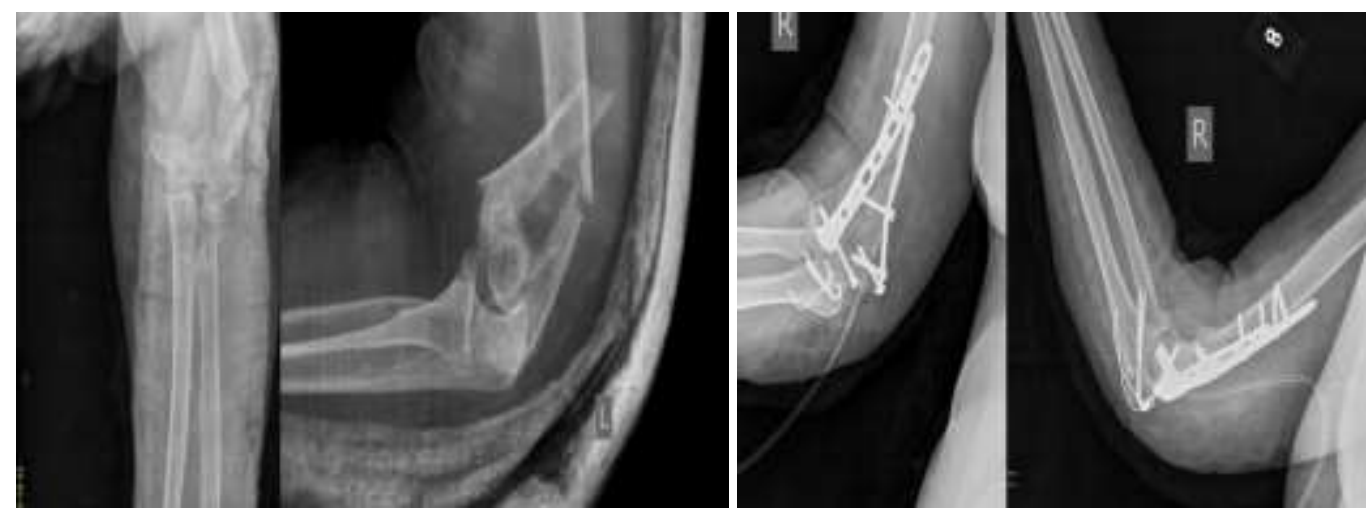

Figure 3: Patient 2, mayo elbow performance score at the end of follow up-82 A) pre-operative X-ray fracture type $13 \mathrm{C} 3, \mathrm{~B})$ post-operative $\mathrm{X}$-ray.
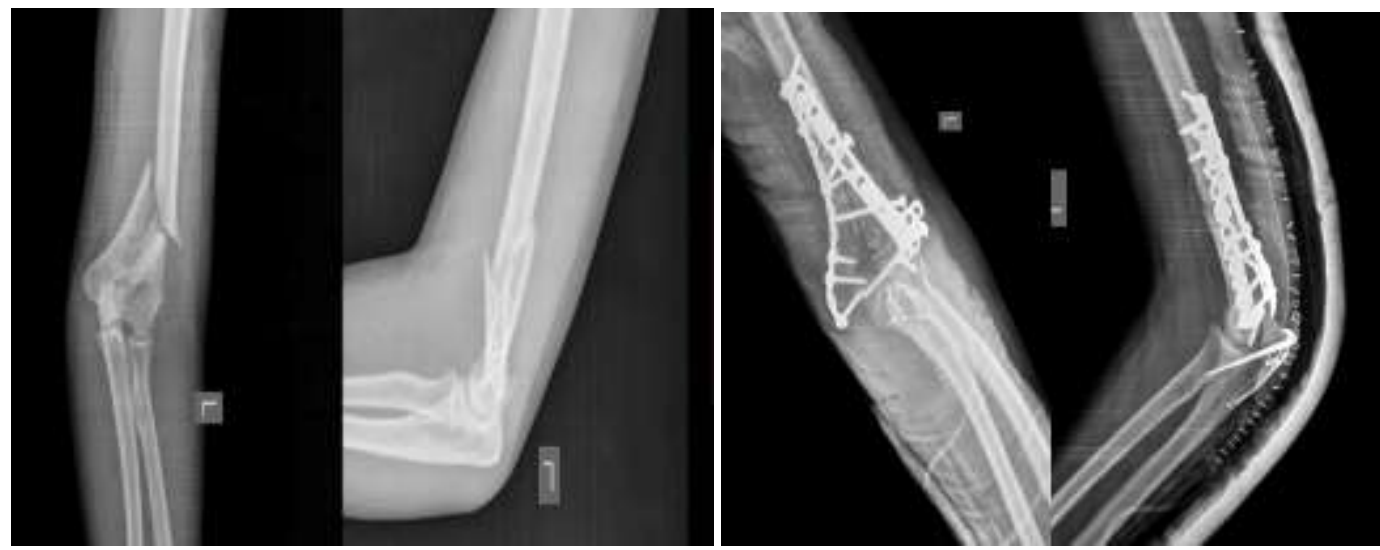

Figure 4: Patient 3, mayo elbow performance score at the end of follow up-90 A) pre-operative X-ray fracture type $13 \mathrm{C} 1, \mathrm{~B})$ post-operative $\mathrm{X}$-ray.
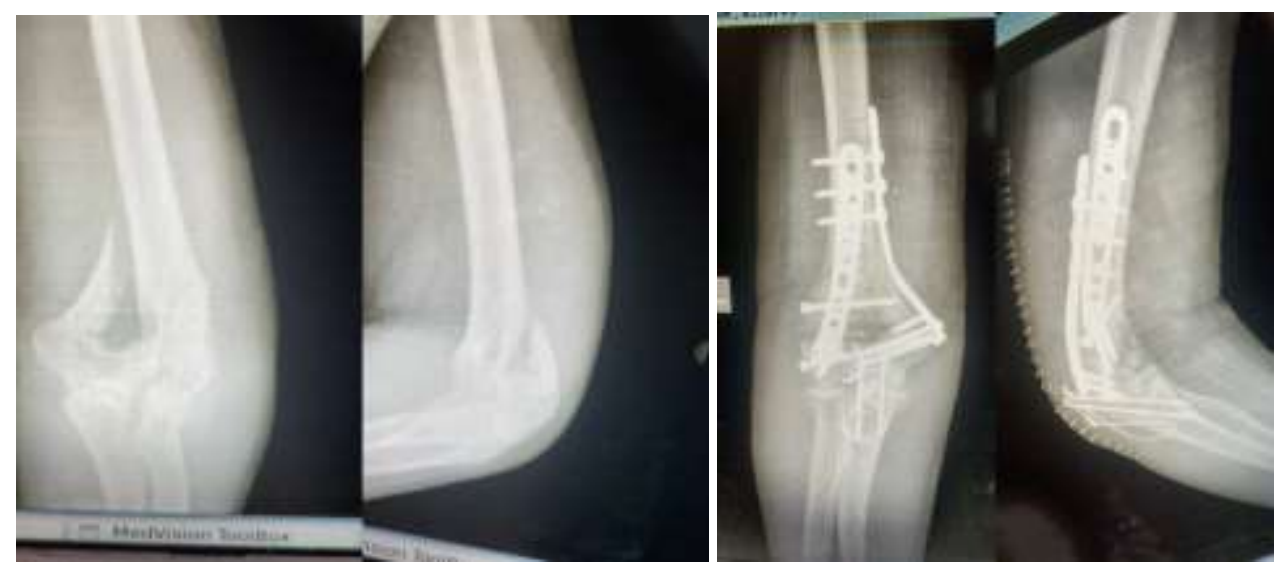

Figure 5: Patient 4, mayo elbow performance score at the end of follow up-81 A) pre-operative X-ray fracture type 13C2, B) post-operative X-ray. 


\section{DISCUSSION}

Distal humerus intra ariicular fractures are must demanding injuries due to complex anatomy, greater degree of comminution involved and age related osteopenia. Although conservative management was followed for many years for such fractures, with advent of improved surgical techniques, morbidities associated with conservative management and demand for faster recovery and return to pre morbid status internal fixation has become preferred modality of treatment principles of internal fixation being absolute articular fixation and stable construct of the columns. The principles starts with selection of appropriate surgical approach. ${ }^{11}$ Due to limited access provided by other approaches many authors advocate olecranon osteotomy as preferred approach particularly in AO type $13 \mathrm{C} 2$ and AO type 13 C3 fractures. However some studies have shown disadvantages of non union and hardware prominence. Argument still exists about the fixation of osteotomy with $\mathrm{k}$ wire tension band wiring, intramedullary screw and plate fixation. ${ }^{12}$ In our study we used fixation of osteotomy with $\mathrm{k}$ wire and tension band wiring. Improved outcomes have been seen with modern fixation devices especially in osteopenic population with locking compression plates over conventional non locking plates with reason being greater cyclic loading failure of locking plates. ${ }^{13}$ Debate still exists on which plate configuration to use and which confers greater stability. Proponents of parallel plating cited greatest construct rigidity and load to failure. ${ }^{14}$ While perpendicular or orthogonal plating configuration offers greatest sagittal plane stiffness, frontal plane and torsional stiffness compared to parallel, triple plating, y plate with regards to biomechanics. ${ }^{15}$ Clinically no difference was demonstrated between parallel and orthogonal plating. In our study perpendicular plate configuration was used.

Non union is usually seen at metaphyseal level rather than articular level due to inadequate fixation and comminution. ${ }^{16}$ In our study no case of non union was seen radiologically. Risk factors associated with non union are extreme comminution and age related osteopenia. In such high risk factors and outcome associated with it, total elbow arthroplasty is a reliable treatment option. ${ }^{17}$ Arthrodesis remains viable option for non reconstructible distal humerus fractures and failed total elbow arthroplasy. ${ }^{18}$

Elbow stiffness was most common complication in yesteryears due to extensive soft tissue disruption, delay in surgery, poor rehabilitation protocol and infections ${ }^{19}$. In our study we had one case of elbow stiffness with infection. Elbow stiffness can be prevented with stringent physiotherapy protocol and rehabilitation and is an effective method of regaining elbow range of motion. In our study functional arc of motion was achieved.

Infections have been reported in distal humerus due to extensive soft tissue dissection. Superficial infections can be managed with antibiotics while deep infection usually requires debridement. Risk factors associated are hematogeous infection, immuno-compromised status, morbid diseases. ${ }^{20}$

Ulnar nerve neuropathy is the most commonly affected nerve due to close proximity to fracture site and manipulation, traction injury to nerve intra operatively and implant related problems. ${ }^{21}$ No consensus have been reached with regards to anterior ulnar nerve transposition. Some authors have found no significant difference in ulnar nerve neuropathy pertaining to nerve transposition. $^{22}$

Heterotopic osssification incidence varies from 0 to 49 percent in distal humerus fractures. ${ }^{23}$ Head injury, surgical delay, prolonged immobilization, bone grafting, extensive muscle injury are the documented risk factors. ${ }^{24}$ Some studies have proposed indomethacin and radiotherapy prophylaxis for heterotopic ossification but evidence is lacking.

Various outcome measures have been used with respect to function like disabilities of the arm, shoulder and hand, mayo elbow performance score, american shoulder and elbow score, patient rated elbow evaluation. In our study we used MEPS for functional outcome due to its accuracy and reliability. ${ }^{25}$ MEPS and range of motion achieved after fixation of various studies are tabulated and results of our study are similar to them(Table 3). In our study no relationship was found between advancing age and MEPS. Risk factors associated with poor functional outcome include extreme fracture comminution, poor bone stock, non compliance to physiotherapy protocol.

Table 3: Comparison of functional outcomes with similar studies.

\begin{tabular}{|c|c|c|c|}
\hline Reference & $\begin{array}{l}\text { No. of } \\
\text { fractures }\end{array}$ & MEPS & $\begin{array}{l}\text { Arc of } \\
\text { motion } \\
\text { (degrees) }\end{array}$ \\
\hline $\begin{array}{l}\text { Athwal } \\
\text { et } \mathbf{a l}^{24}\end{array}$ & 32 & $\begin{array}{l}\text { Mean } \\
\text { MEPS } 82\end{array}$ & 97 \\
\hline Liu et $\mathbf{a l}^{25}$ & 32 & $\begin{array}{l}\text { MEPS } \\
\text { excellent } \\
78 \% \\
\text { MEPS } \\
\text { good } \\
22 \%\end{array}$ & $\begin{array}{l}22 \text { to } \\
125\end{array}$ \\
\hline $\begin{array}{l}\text { Doornberg } \\
\text { et } \mathbf{a l}^{26}\end{array}$ & 30 & MEPI 91 & 106 \\
\hline $\begin{array}{l}\text { Mckee } \\
\text { et } \mathbf{a l}^{11}\end{array}$ & 25 & MEPS 91 & 108 \\
\hline $\begin{array}{l}\text { Bhayana } \\
\text { et } \mathbf{a l}^{27}\end{array}$ & 94 & MEPS 88.4 & 120.39 \\
\hline
\end{tabular}

The limitations of our study were small sample size, comparative study between various surgical approaches, 
plate configuration. Study regarding ulnar nerve transposition not done as it would affect our outcome. Due to different fracture configuration clinical results may differ.

\section{CONCLUSION}

In our study good functional results in terms of mayo elbow performance score and arc of motion have been obtained in intra articular distal humerus fractures AO type $13 \mathrm{C}$. We also conclude that olecranon osteotomy provides an excellent visualization of fracture fragments. Orthogonal locking plate configuration provides greater stability. Better functional outcome was augmented by stringent post operative physiotherapy protocol, proper planning and meticulous surgical exposure.

Funding: No funding sources

Conflict of interest: None declared

Ethical approval: The study was approved by the institutional ethics committee

\section{REFERENCES}

1. Robinson CM, Hill RM, Jacobs N, Dall G, CourtBrown CM. Adult distal humeral metaphysical fractures: epidemiology and results of treatment. J Orthop Trauma. 2003;17:38-47.

2. Palvanen M, Kannus P, Niemi S, Parkkari J. Secular trends in the osteoporotic fractures of the distal humerus in elderly women. Eur J Epidemiol. 1998; 14(2):159-64.

3. Riseborough EJ, Radin EL. Intercondylar T Fractures of the humerus in the adult, A comparison of operative and non-operative treatment in twenty-nine cases. J Bone Joint Surg Am. 1969;51(1):130-41.

4. Eastwood WJ. The T-shaped fracture of the lower end of the humerus. JBJS. 1937;19(2):364-9.

5. Evans EM. Supracondylar-Y fractures of the humerus. The journal of bone and joint surgery. British Volume. 1953;35(3):381-5.

6. Schindelar LE, Rondon AJ, Ilyas AM. Total elbow arthroplasty versus open reduction and internal fixation for the management of distal humerus fractures in the elderly. Orthopedics. 2018;42(1):227.

7. Wilkinson JM, Stanley D. Posterior surgical approaches to the elbow: a comparative anatomic study. J Shoulder Elbow Surg. 2001;10(4):380-2.

8. Coles CP, Barei DP, Nork SE, Taitsman LA, Hanel DP, Henley MB. The olecranon osteotomy: a sixyear experience in the treatment of intraarticular fractures of the distal humerus. Journal of Orthopaedic Trauma. 2006;20(3):163-70.

9. Snow M, Thompson G, Turner PG. A mechanical comparison of the locking compression plate (LCP) and the low contact-dynamic compression plate (DCP) in an osteoporotic bone model. Journal of Orthopaedic Trauma. 2008;22(2):121-5.
10. Bogataj M, Kosel F, Norris R, Krkovic M, Brojan M. Biomechanical study of different plate configurations for distal humerus osteosynthesis. Med Biol Eng Comput. 2015;53(5):381-92.

11. Mckee MD, Kim J, Kebaish K, Stephen DJ, Kreder HJ, Schemitsch EH. Functional outcome after open supracondylar fractures of the humerus: the effect of the surgical approach. The Journal of Bone and Joint Surgery. British Volume. 2000;82(5):646-51.

12. Nijs S, Graeler H, Bellemans J. Fixing simple olecranon fractures with the olecranon osteotomy nail (oleon). Oper Orthop Traumatol. 2011;23:43845.

13. Korner J, Diederichs G, Arzdorf M, Lill H, Josten C, Schneider E, et al. A biomechanical evaluation of methods of distal humerus fracture fixation using locking compression plates versus conventional reconstruction plates. Journal of Orthopaedic Trauma. 2004;18(5):286-93.

14. Schemitsch EH, Tencer AF, Henley MB. Biomechanical evaluation of methods of internal fixation of the distal humerus. J Orthop Trauma. 1994;8(6):468-75.

15. Jacobson SR, Glisson RR, Urbaniak JR. Comparison of distal humerus fracture fixation: a biomechanical study. J The Southern Orthop Assoc. 1997;6(4):2419.

16. Helfet DL, Kloen P, Anand N, Rosen HS. Open reduction and internal fixation of delayed unions and nonunions of fractures of the distal part of the humerus. JBJS. 2003;85(1):33-40.

17. Goodman AD, Johnson JP, Kleiner JE, Gil JA, Daniels AH. The expanding use of total elbow arthroplasty for distal humerus fractures: a retrospective database analysis of 56,379 inpatients from 2002-2014. The Physician And Sportsmedicine. 2018;46(4):492-8.

18. Reichel LM, Wiater BP, Friedrich J, Hanel DP. Arthrodesis of the elbow. Hand Clinics. 2011;27(2): 179-86.

19. Koh KH, Lim TK, Lee HI, Park MJ. Surgical release of elbow stiffness after internal fixation of intercondylar fracture of the distal humerus. J Shoulder Elbow Surg. 2013;22(2):268-74.

20. Lawrence TM, Ahmadi S, Morrey BF, SánchezSotelo J. Wound complications after distal humerus fracture fixation: incidence, risk factors, and outcome. J Shoulder Elbow Surg. 2014;23(2):25864.

21. Worden A, Ilyas AM. Ulnar neuropathy following distal humerus fracture fixation. Orthop Clin North Am. 2012;43(4):509-14.

22. Chen RC, Harris DJ, Leduc S, Borrelli JJ, Tornetta III P, Ricci WM. Is ulnar nerve transposition beneficial during open reduction internal fixation of distal humerus fractures?. Journal of Orthopaedic Trauma. 2010;24(7):391-4.

23. Douglas K, Cannada LK, Archer KR, Dean DB, Lee $\mathrm{S}$, Obremskey $\mathrm{W}$. Incidence and risk factors of 
heterotopic ossification following major elbow trauma. Orthopedics. 2012;35(6):E815-22.

24. Athwal GS, Hoxie SC, Rispoli DM, Steinmann SP. Precontoured parallel plate fixation of AO/OTA type $\mathrm{C}$ distal humerus fractures. Journal of orthopaedic trauma. 2009 Sep 1;23(8):575-80.

25. Liu JJ, Ruan HJ, Wang JG, Fan CY, Zeng BF. Double-column fixation for type $\mathrm{C}$ fractures of the distal humerus in the elderly. Journal of shoulder and elbow surgery. 2009 Jul 1;18(4):646-51.

26. Doornberg JN, Van Duijn PJ, Linzel D, Ring DC, Zurakowski D, Marti RK, Kloen P. Surgical treatment of intra-articular fractures of the distal part of the humerus: functional outcome after twelve to thirty years. JBJS. 2007 Jul 1;89(7):1524-32.

27. Bhayana H, Pandey R, Dhammi IK, Baumann F, Bhatia U. Comparative study for assessment of functional outcome of intraarticular AO Type C distal humerus fractures treated by parallel plating. Indian Journal of Orthopaedics. 2019 Feb;53:190-5.

Cite this article as: Mohammed FS, Ingale AB. Evaluation of functional outcome after osteosynthesis of intra articular distal humerus fracture with pre contoured locking compression plates. Int J Res Orthop 2020;6:1215-21. 